\title{
MEDIAÇÃO PEDAGÓGICA NO CONTEXTO DA EDUCAÇÃO A DISTÂNCIA NO ENSINO SUPERIOR
}

\author{
LONDRINA/PR JULHO/2018
}

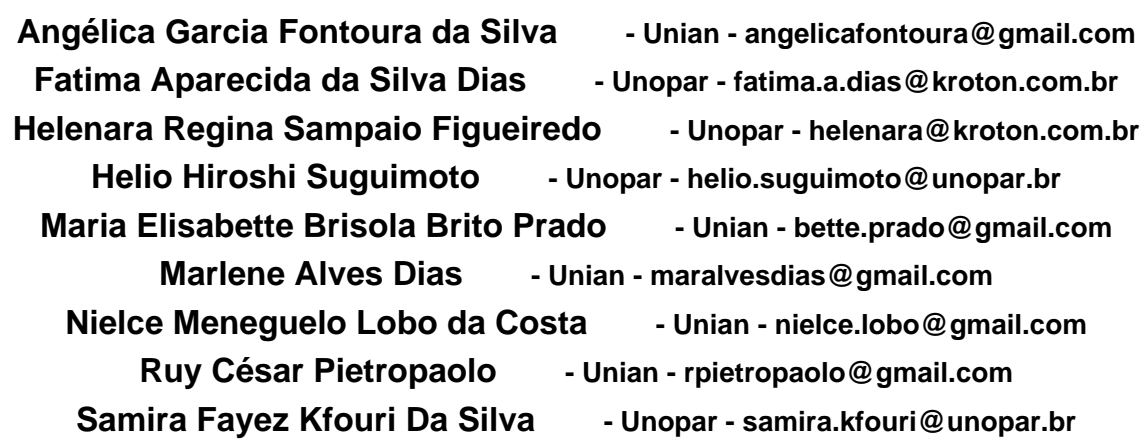

Tipo: Relato de Experiência Inovadora (EI)

Categoria: Estratégias e Políticas

Setor Educacional: EDUCAÇÃO SUPERIOR

\begin{abstract}
RESUMO
O objetivo deste artigo é apresentar a experiência de pesquisadores ao desenvolverem um projeto de pesquisa em um processo de Formação Continuada em Serviço ofertado em Ambiente Virtual de Aprendizagem. Esse projeto contemplou a elaboração de um curso para desenvolver aspectos da mediação pedagógica no contexto de um curso de Letramento Estatístico ofertado para tutores das Universidades: Pitágoras Unopar e Anhanguera EAD, localizadas na cidade de Londrina, Paraná. $O$ referencial teórico que norteou a concepção do curso e as análises de dados coletados se constituiu, inicialmente, pelas pesquisas e estudos relacionados ao Letramento Estatístico baseado nas ideias de Gal, Cazorla e Castro e no âmbito da Educação a Distância que prioriza a importância da Mediação Pedagógica nos estudos de Alves, Tori, Prado, Almeida, Valente e Moran dentre outros. Um dos resultados da experiência foi a permanência dos participantes no curso e a análise revelou que a estratégia de acompanhamento presencial e a distância feita pela equipe gestora do curso junto aos tutores foi fundamental, pois permitiu a reflexão e o aprendizado na ação sobre a mediação pedagógica e a forma de intervir no processo de aprendizagem.
\end{abstract}

Palavras-chave: mediação pedagógica; formação continuada; educação a distância; letramento estatístico. 


\section{Introdução}

$\mathrm{Na}$ investigação sobre a aprendizagem no contexto da EAD, o papel da mediação é elemento central. Neste artigo apresentamos a experiência de um grupo de pesquisadores ao desenvolverem um projeto de pesquisa em um processo de Formação Continuada em Serviço ofertado em Ambiente Virtual de Aprendizagem.

Para este grupo de pesquisadores o desenvolvimento de uma investigação que busca a compreensão de quais fatores podem favorecer a reflexão e a ressignificação do processo interativo em cursos desenvolvidos em ambientes virtuais torna-se relevante para a promoção da aprendizagem dos participantes (tutores e professores mediadores). Nessa perspectiva foi apresentado o projeto de pesquisa intitulado Mediação em EAD: contexto de um curso de Letramento Estatístico, que se desenvolveu pela criação, implementação e realização de um curso de extensão sobre letramento estatístico, pautado nos estudos de Gal (2002) e os de Cazorla e Castro (2008). O objetivo principal da pesquisa foi a de identificar quais características desse curso, desenvolvido na modalidade semipresencial, poderiam favorecer aos profissionais que atuam na tutoria de cursos em EaD, particularmente de duas Universidades envolvidas, a refletirem sobre as práticas da mediação pedagógica e a ressignificarem o processo interativo no contexto online.

\section{Fundamentação Teórica}

Os estudos relativos a Educação a Distância e suas possibilidades para promover diversas formas de ensinar e aprender, eixo no qual nos apoiamos, envolveram as pesquisas e estudos de Alves (2006), Prado (2006), Tori (2010), Nunes (2009), Valente e Moran (2011). Para analisar a concepção de Mediação Pedagógica utilizamos os pressupostos apresentados por Masetto (2000) para fundamentar a mediação pedagógica online e presencial, para a Mediação Afetiva os estudos de Silva, (2012) e para mediação das questões administrativas e operacionais, utilizamos os referenciais de qualidade para Educação superior à distância do Ministério da Educação, (2007). Esses autores e os referenciais de qualidade destacam o papel do professor e do tutor online como criador de estratégias e de espaços interativos de diálogos para proporcionar a aprendizagem do aluno virtual.

O tutor faz a mediação tecnológica e humana no contexto de ensino e da aprendizagem. No entanto, independente dos recursos tecnológicos que sejam utilizados na EAD é essencial proporcionar aos estudantes a interação e a integração com a proposta pedagógica do curso o qual está cursando. Para isto, o tutor precisa gerenciar situações 
diversas, criar e manter 0 interesse dos estudantes sobre os temas abordados, ser incentivador e acompanhar o percurso de aprendizagem dos alunos. Essas ações, que geralmente ocorrem em turmas com grande número de alunos com formações heterogêneas, com vivências e culturas diversas, demanda do tutor habilidade gerencial para fazer as intervenções adequadas no processo de aprendizagem.

Segundo Masetto (2000), a intervenção "se apresenta com a disposição de ser uma ponte - não uma ponte estática, mas uma ponte rolante, [...] que ativamente colabora para que o aprendiz chegue aos seus objetivos" (p. 144-145). Isso significa que a mediação pedagógica online não é algo simples de ser compreendida e colocada em prática. É necessário contemplar ao mesmo tempo a dimensão afetiva, cognitiva e operacional. Esse tem sido um dos grandes desafios na EAD. A mediação afetiva está presente na mediação realizada pelo tutor, como Almeida (1999, p. 107) ressalta quando afirma que "as relações afetivas se evidenciam, pois, a transmissão do conhecimento implica, necessariamente, uma interação entre pessoas. Portanto, na relação professoraluno, uma relação de pessoa para pessoa, o afeto está presente".

A mediação operacional está ligada às questões administrativas - como acesso aos materiais, boletos, matrículas, agendamento de provas, atestados - os tutores repassam ao setor responsável para dar retorno aos alunos, conforme previsto nos Referenciais de Qualidade para Educação Superior a Distância (BRASIL, 2007, p. 23):

No que tange à dimensão administrativa, a equipe deve atuar em funções de secretaria acadêmica, no registro e acompanhamento de procedimentos de matrícula, avaliação e certificação dos estudantes, envolvendo o cumprimento de prazos e exigências legais em todas as instâncias acadêmicas; bem como no apoio ao corpo docente e de tutores nas atividades presenciais e a distância, distribuição e recebimento de material didático, atendimento a estudantes usuários de laboratórios e bibliotecas, entre outros.

É fato que o processo de mediação realizado pelos tutores envolve aspectos que vão além dos conteúdos do curso, diante disso, faz-se necessário que os profissionais que atuam na mediação estejam envolvidos nos processos da instituição para que as mediações pedagógica, afetiva e operacional se efetivem.

\section{O Projeto de Mediação no contexto de um curso de Letramento Estatístico}

O projeto Mediação em EAD: contexto de um curso de Letramento Estatístico do Programa de Formação da Universidade foi concebido a partir da integração entre dois Programas de Pós-graduação sediados em cidades distintas, os quais, por meio de seus 
pesquisadores em Formação docente e em tecnologia, elaboraram um projeto de formação continuada e de pesquisa tendo como objetivo principal implementar um curso de extensão para tutores que atuavam em cursos das referidas instituições, oferecidos na modalidade a distância. Para esses profissionais a formação deveria se apresentar como um momento no qual os participantes vivenciassem, no papel de alunos, situações envolvendo mediação pedagógica, entendida como fundamental à docência em EAD. Para viabilizar esse processo formativo, foi decidido que o contexto de estudo fosse 0 Letramento Estatístico. Essa escolha se deu pelo fato do letramento em Estatística estar presente na vida do cidadão e nas mais diversas profissões, assim sendo, caracterizavase como um conteúdo a atingir os tutores atuantes nos mais variados cursos. Ser letrado estatisticamente pressupõe organizar os dados, analisá-los, tomar decisões, comunicar, eficientemente, as informações coletadas e argumentar conscientemente a aceitação das conclusões fornecidas e assim tomar decisões baseadas em dados (GAL, 2002). 0 letramento estatístico denota um conhecimento de conceitos e procedimentos estatísticos básicos, que favorecem a elaboração de argumentação a partir da análise crítica de informações encontradas encontrados em diversas situações.

No caso desse curso, como os trezentos participantes, das seis turmas, tinham formação em diferentes áreas do conhecimento, esse conteúdo foi considerado acessível para que experienciassem como alunos as características da mediação na sua dimensão operacional, afetiva e pedagógica.

O curso com carga horária de 120 horas, distribuídas em encontros presenciais e à distância, teve por objetivo, como já citado, identificar quais aspectos da mediação poderiam favorecer aos profissionais que atuam na EAD a refletirem sobre a prática de tutoria. Para isso, os conteúdos foram estruturados em três módulos, como segue:

Módulo 1:

- Leitura e interpretação de representações gráficas

- Preparo de um Projeto de Pesquisa Estatística

Módulo 2:

- Medidas de Tendência Central

- Desenvolvimento da Pesquisa Estatística 
Módulo 3:

- Desvio Padrão

- Elaboração do relatório da Pesquisa Estatística

No curso Letramento Estatístico foram discutidos noções e conceitos de Estatística por meio da participação ativa em atividades realizadas individualmente ou em grupos. Além disso, o curso propôs o desenvolvimento de diversas atividades, com cenários associados à situações cotidianas apresentadas no formato de estudo de casos, histórias em quadrinhos e vídeos visando auxiliar na aprendizagem e na reflexão sobre o uso da Estatística. Além disso, o curso propôs o desenvolvimento de uma Pesquisa Estatística, na qual os grupos de tutores utilizaram os conceitos e as noções estudadas no decorrer do curso. O conteúdo foi estruturado em um Ambiente Virtual de Aprendizagem (AVA Stricto) customizado na plataforma Moodle, especificamente para atender aos objetivos do curso, já mencionados. A mediação pedagógica no AVA-Stricto foi desenvolvida por quinze docentes, denominados professores mediadores, que atuavam na graduação EaD. Esses docentes receberam formação específica sobre o conteúdo do curso e aspectos da mediação, além de serem acompanhados semanalmente pelos gestores do curso - docentes pesquisadores do programa Stricto Sensu.

\section{Resultados e discussão}

Durante o curso foram coletados e analisados diversos dados, desde questionários aplicados aos cursistas até registros textuais extraídos do AVA-Stricto. Dos dados analisados selecionamos para apresentar neste artigo, parte do relatório elaborado no final do módulo 2 o qual apresentou informações relativas ao número de inscritos, quantidade de atividades entregues, além de críticas e sugestões em relação ao AVAStricto, ao cronograma e aos prazos. Destes, apresentamos a seguir, a análise do número de inscritos, desistentes e permanentes em cada turma, conforme mostra o quadro 1. 
Quadro 1: Quantidade de cursistas

\begin{tabular}{|c|c|c|c|}
\hline Turmas & Inscritos & Desistentes & Permanentes \\
\hline Turma 1 & 38 & 5 & 33 \\
\hline Turma 2 & 37 & 1 & 36 \\
\hline Turma 3 & 45 & 7 & 38 \\
\hline Turma 4 & 46 & 7 & 39 \\
\hline Turma 5 & 46 & 5 & 41 \\
\hline Turma 6 & 36 & 3 & 33 \\
\hline Total & $\mathbf{2 4 8}$ & $\mathbf{2 8}$ & $\mathbf{2 2 0}$ \\
\hline
\end{tabular}

Fonte: Elaborado pelo autor (2018)

Analisando o quadro 1, observamos que as turmas mantiveram uma média de cursistas, por ter sido uma formação em serviço, inferimos que o número de desistentes diminuiu devido ao desligamento de alguns tutores no final do semestre por possuírem contrato semestral nas Universidades citadas.

O acompanhamento a distância ocorreu por meio de relatórios e ferramentas disponíveis no AVA-Stricto, como por exemplo, fóruns, envio de mensagens e e-mail. $O$ acompanhamento presencial, considerado na análise como um ponto relevante nesse projeto, ocorreu semanalmente, por meio de plantões ora agendados entre gestores do projeto e professores mediadores ora entre gestores do projeto e cursistas. Tais encontros tiveram como objetivo principal discutir aspectos da mediação pedagógica, afetiva e operacional, que são essenciais para a participação dos estudante no curso. (MASETTO, 2000). Nesses plantões os cursistas e professores mediadores esclareceram dúvidas técnicas e socializaram dificuldades sobre o andamento do curso. Esses foram fundamentais, por exemplo, para dar suporte à elaboração e desenvolvimento da atividade de Pesquisa Estatística, tal atividade perpassou todos os módulos e foi desafiadora para os cursistas, pois como salientam Cazorla e Castro (2008) os cursistas conseguiram atribuir significado para o aprendizado da estatística no processo de realizar a atividade de pesquisa. Além disso, nos encontros presenciais foi possível socializar as dúvidas e discutir como mediar situações de atrasos de entrega de atividades, as dificuldades de comunicação entre os cursistas e os professores e as estratégias de como manter os participantes motivados e, consequentemente, a permanência dos mesmos no curso.

A partir do acompanhamento presencial foi possível reestruturar alguns pontos previstos a priori no curso, rever e discutir a prática usual de forma a mostrar que as dificuldades encontradas diariamente por professores, tutores e estudantes são advindas da 
mediação pedagógica.

Percebemos que a estratégia de acompanhamento presencial e a distância realizada pela equipe gestora do curso junto aos tutores e professores mediadores foi fundamental, pois permitiu a reflexão e o aprendizado na ação sobre a mediação pedagógica e a forma de intervir no processo de aprendizagem por meio das diferentes ferramentas síncronas e assíncronas de interação viabilizadas pelo AVA. A esse respeito Prado (2006) destaca que os materiais de apoio e o tipo de atividade proposta no curso também são vistas como mediadoras do processo de aprendizagem.

A experimentação de um curso de Letramento Estatístico, visou reflexões e discussões paralelas a respeito de aspectos da mediação pedagógica, afetiva e operacional uma vez que, tutores e professores vivenciaram situações no papel de estudantes. A mediação pedagógica se constitui como uma importante função dos tutores da Universidade, visto que são os intérpretes dos cursos oferecidos na modalidade EaD, para subsidiar o aluno na construção do conhecimento.

Nesse contexto, foi possível observar que a criação e desenvolvimento do curso de letramento estatístico, baseado nos princípios apontados por Gal (2002), promoveu vivências sobre mediação e favoreceu a discussão e reflexão sobre os limites e possibilidades da mediação pedagógica.

\section{Considerações finais}

A proposta de utilizar o Letramento Estatístico como contexto para refletir sobre a mediação pedagógica auxiliou a compreender melhor quais as ferramentas do AVAStricto foram privilegiadas pelos participantes e, assim sendo, consideramos que estas se mostraram essenciais para realizar a mediação.

Consideramos como ponto essencial em um processo de mediação, o acompanhamento presencial aos cursistas e professores mediadores, visto que nesse curso revelou a necessidade de explicitar melhor o que se espera deles, ou seja, nem sempre o que supomos estar comunicando é o que o receptor está compreendendo.

Finalizando, acrescentamos que, além do acompanhamento presencial, enfatizamos a necessidade de disponibilizar momentos e espaços de discussão a distância destinados à formação. 


\section{Referências}

ALVES, J. R. M. A nova regulamentação da EAD no Brasil. Educação online, v. 2, 2006.

BRASIL. MINISTÉRIO DA EDUCAÇÃO. Secretária de Educação a Distância. Referencial de qualidade para os cursos a Distância. Brasília. Ago. 2007. Disponível em:<http://portal.mec.gov.br/seed/arquivos/pdf/legislacao/refead1.pdf> . Acesso em: 20 de set. 2017.

CAZORLA, I. M.; CASTRO, F. C. O Papel da Estatística na Leitura do Mundo: o letramento estatístico. Publicatio UEPG. Ciências Humanas, Ciências Sociais Aplicadas, Lingüística, Letras e Artes, v. 16, p. 45-53, 2008.

GAL, I. Adults' statistical literacy: Meanings, components, responsibilities. International statistical review, v. 70, n. 1, p. 1-25, 2002.

MASETTO, M. T. Mediação pedagógica e o uso da tecnologia. IN: MORAN, J. M.; MASETTO M. T; BEHRENS, M. A. Novas tecnologias e mediação pedagógica. Campinas: Papirus, 2000.

NUNES, I. B. A História da EaD no Mundo. In: LITTO, F. M.; FORMIGA, M. (orgs.). Educação a Distância: o estado da arte. São Paulo: Pearson Education do Brasil, 2009.

PRADO, E. B. M.. A Mediação Pedagógica: suas relações e interdependências. In: Brazilian Symposium on Computers in Education (Simpósio Brasileiro de Informática na Educação-SBIE), 2006. p. 101-110.

SILVA, J. S. D. A ação docente na EaD: A mediação do tutor entre o discurso e a prática. (Dissertação de Mestrado) - Universidade Federal de Pernambuco, 2012.

TORI, R. Educação sem distância - as tecnologias interativas na redução de distâncias em ensino e aprendizagem. São Paulo: Editora Senac São Paulo, 2010. 